Article

\title{
Sustainable Development Mechanism of Food Culture's Translocal Production Based on Authenticity
}

\section{Guojun Zeng *, Yongqiu Zhao ${ }^{\dagger}$ and Shuzhi Sun ${ }^{\dagger}$}

School of Tourism Management, Sun Yat-sen University, Guangzhou 510275, China;

E-Mails: zhaoyq@mail2.sysu.edu.cn (Y.Z.); sunshzh3@mail2.sysu.edu.cn (S.S.)

$\dagger$ These authors contributed equally to this work.

* Author to whom correspondence should be addressed; E-Mail: zenggj@mail.sysu.edu.cn; Tel.: +86-138-2640-2696.

External Editor: Shangyi Zhou

Received: 23 June 2014; in revised form: 28 August 2014 / Accepted: 19 September 2014 /

Published: 13 October 2014

\begin{abstract}
Food culture is a kind of non-material culture with authenticity. To achieve sustainable development of translocal heritage and food culture, we must protect its authenticity. By selecting the cases of the Dongbeiren Flavor Dumpling Restaurant and the Daozanjia Northeast Dumpling Restaurant and using the in-depth interview method, this study discusses how northeastern Cuisine in Guangzhou balances the inheritance and innovation of authenticity, how producers and customers negotiate, and how to realize sustainable development. The main conclusions are: first, there are two different paths of translocal food culture production, which are "authentic food culture production" and "differentiated food culture production". Second, what translocal enterprises produce is not objective authenticity, but constructive authenticity, or even existential authenticity. Third, compared with differentiated food culture production, authentic food culture production is helpful for the sustainable development of local food culture production. It protects the locality while transmitting and developing the local culture. Fourth, translocal food culture production is a process in which the producers and consumers continue to interact to maintain a state of equilibrium, which informs the sustainable development mechanism with a high degree of authenticity.
\end{abstract}


Keywords: food; locality; translocality; authenticity; cultural production; sustainable development

\section{Introduction}

Geographical ecology, farming traditions and local culture shape the tastes of different places, so eating habits vary from place to place $[1,2]$, and food becomes an important characterization of locality [3]. Particular food regions are gradually formed. In China, an important characteristic of food regional differentiation is local flavor dishes based on different regions, such as the most famous big four cuisines, which are Shandong cuisine, Huaiyang cuisine, Sichuan cuisine, and Cantonese cuisine. However, now, in the age of globalization, which is an unprecedented "time-space compression" era, economic and cultural forces break traditional space limits and reconstruct the space and local construction methods and organizational forms on a larger scale [4]. In this process, local cuisine, the diet of different ethnic groups, and food associated with a particular class are initially produced locally, and then gradually spread with immigration [5]. Local food culture constantly moves with translocal production from its food region and in the process of constant collision, conflict, communication, understanding and identity with other characteristic food culture, a certain cultural fusion become inevitable. As we all know, cultural fusion has been the overall trend in the development of cross-culture communication, and it may eventually form a kind of "variation" of the original cultural system.

In recent years, the sustainable development of food culture has had increasing attention from researchers. It requires a start from the innovation of traditional food culture and to measure its new vitality constantly. In addition, it is the inheritance and development of food culture characteristics. At the original place of the food, for the consumers, "local" foods are associated with a host of values, such as being better for the environment, conserving "traditional" rural landscapes and supporting the local economy. There is, therefore, a "feel-good" factor associated with consuming them [6], which is helpful to its sustainable development. However, food culture faces the predicament of sustainable development in the translocal production process. First, there is the danger that localization is likely to be lost or redefined [7-9]. The development of the culture, or its communication with different cultures, can lead to changes in content and structure [10], which is not conducive to the inheritance and development of traditional food culture. Second, a dilemma constantly exists between keeping the culture's authenticity and implementing standardization in the spread of translocal food culture [11]. Whether translocal culture production is "unconscious inheritance" or "conscious creation", those problems, such as "paradox between culture protection and innovation" and "dilemma between authenticity and standardization", haven't been fully resolved. Thus, it is necessary to supplement the research on translocal production mechanism of food culture and explore how to realize sustainable development from the perspective of process. This paper uses the method of case study, which selects the production process of northeastern cuisine restaurants in Guangzhou. The study combines the concepts of translocality, authenticity and food culture production with the adoption of cultural geography theory. It will play a role in promoting the translocation development of translocal culture production, sustainable development theory, and diet geography. 


\section{Literature Review}

\subsection{Food Culture and its Production}

Current academic circles do not form a unified definition about the concept of food culture [12,13]. Xiaomei Cai et al. summarized food culture as "the technology, science and art in the process of development and utilization of food materials, food production and consumption, and the customs, traditions, thoughts and philosophy based on diet, namely, the sum of all food things combined with structures such as the process methods and functions of food production and food life" [14]. Rongguang Zhao et al. had the opinion that the cultivation, selection, preparation, production and consumption of food was an expression of social culture, because food production was not only for eating, but also contained purposes of ceremony, activity and aesthetics [15,16]. Diet geography's study of food culture emphasizes the relationship between people and place, the geographical differentiation regularity, and the influence of geographical environment on food culture [2,16-18]. Meanwhile, scholars in the management field focus on the research on food culture from the angle of enterprise management to explore how to use the authenticity and diversity of food culture to provide support for the expansion of enterprise [11,19].

The core concept of culture production lies in how the cultural connotation is created, allocated, evaluated, educated and saved [20,21], and it involves three problematical aspects: the relationship between the physical and aesthetic characterization, the production process of characterization, and the additional social and economic values attached to it [22]. Food has been regarded as one form of physical characterization of culture [23]. Culture is not a kind of static entity high above the masses; it constantly changes for being reimagined and constructed in different historical situations [24,25]. New culture geography has just begun to pay serious attention to culture production [26]. Scholars not only focus on material culture landscape, but also on intangible cultural landscapes, such as food culture, and start to dig into the multiple meanings behind the cultural landscape [27], explain the deep cultural concepts inside it, and focus on research on small scale cultural space and cultural production [18]. Tourism researchers also begin to pay attention to the paradox between authenticity and standardization in the development of catering enterprises [11,19]. Most studies focus on local cultural elements that people identify with [28], while locality as the carrier of food culture authenticity, often is ignored by food geography researchers [1].

\subsection{Locality and Translocality}

Place bears subjectivity $[29,30]$. In the context of humanistic geography, place is defined as a "perceived value center", and the carrier of cultural and social significance [8,31]. The significance of place is also closely related with the construction of an individual or social group's identity [8,32]. Locality is the key difference that distinguishes one place from another [33]. A long-term accumulation of cultural connotation, and people's identity of the culture, help a place form its locality [34]. Mitchell D. thinks that when one place establishes functional contact with the outside world, the internal condition it has, which is not possessed by other places, is locality [35]. Namely, locality is created after people give meaning to the space, and it is the excavation of the uniqueness of local culture. 
In the background of globalization, a large quantity of immigration takes place [36]. The frequent migrations of people and enterprises have broken the established boundaries and changed the cultural significance and status of places [37]. The traditional understanding of state, society and culture has been thoroughly subverted, thus more and more "translocalities" have been developed, and translocal food is now commonly seen. Food culture is no longer a phenomenon of fossilization confined to particular countries and national boundaries, but a continuous social process refactored in cultural integration [38]. Globalization is not a process to remove locality, but to redefine it and produce a new one in a new relationship system [7-11,39].

\subsection{Authenticity of Food Culture}

Authenticity is often thought as a kind of "performance of reality", including two aspects: "genuine" and "sincere" [40,41]. In the experimental study, authenticity implies the connotation of local culture [42]. What tourists go through are anamorphic experiences designed by tourism marketing experts called staged authenticity [40]. Based on this criteria, Ning Wang distinguishes authenticity into three forms: objective, constructive and existential authenticity [41,43]. As authenticity is a factor in tourism motivation and satisfaction of the tourism experience, it is a dilemma whether tourism motivation is to give up the pursuit of authenticity [44], or to just look for it $[40,45,46]$. In addition, authenticity should be subject-involved and interactive instead of one-way for tourist objects [47]. Because authenticity may be objective or constructed, the authenticity tourists experience depends on "the overall experience", and its significance for them. Tourist satisfaction depends on the destination object, and is related with awareness of environment and individual different needs of authenticity [48].

The understanding of authenticity of the same food culture will produce different results depending on the varied concept of authenticity. Although authenticity has an undisputed role meaning, but so far, for researchers, evaluation criteria of authenticity in restaurants are still inconclusive [49]. Food culture shows negotiated authenticity [50-54], customized authenticity [55], replicable authenticity [56], and learned or evoked authenticity [57]. These views are associated with food culture authenticity of constructivism. Those differences of consumers will affect the perceived results of authenticity. Translocal production of food culture belongs to the category of cultural production, and needs to focus on the customers' perception of authenticity. Food culture is not static, and appropriate adjustments and improvements need to be made based on local market demand. In the process of translocal production of food culture, producers and consumers will continue to interact with each other [12], which is reflected in a variety of factors presented to consumers by catering businesses, including restaurant environment [25-27], dishes design [58,59] and staff [25], etc. Authenticity is presented or changed based on these factors, and thus food culture is an ongoing continuous construction.

\subsection{Food Culture, Authenticity and Sustainable Development}

Food culture is the accumulation and precipitation of local culture, and its cultural heritage is much more perceivable than other non-material culture [60]. At the same time, it is an important part of tourism culture, and a kind of excellent folk tourism resource [61]. Therefore, the sustainable development of food culture is particularly important to the heritage and development of local culture, and essential in the promotion and development of the tourism economy. The sustainable development of food culture 
requires one to start from the innovation of traditional food culture, get new vitality from the social changes, keep the critical spirit while experiencing foreign culture shock and the growth of modernity, and to form their own goals, dynamics, strategy and development path based on future development requirements [62]. Scholars who put forward suggestions and countermeasures on how to realize the sustainable development of food culture, such as paying attention to the implementation of brand strategy, adhering to the local characteristics, improving the service system [63], advocating green food [61], and realizing the sustainable development of food production system, etc. [64,65]. At present, there is limited research on sustainable development of food culture, so a definitive research mechanism has not yet been established.

In addition, food culture is a typical non-material culture, and authenticity is its essence and soul [66]. It helps food culture to form a monopoly, promote appeal, and enhance brand penetration. As one of the important principles of cultural heritage protection, authenticity decides the heterogeneity of food culture and is helpful in improving the sustainable attraction of food culture [67]. Goodman and Oakes et al. believe that the pursuit of authenticity experience in translocal restaurants is an important trend $[68,69]$. Authenticity of food culture is the determinant of successful operation of translocal food businesses $[42,66]$. To achieve the sustainable development of food culture, we must protect its authenticity, and this paper discusses a methodology for and mechanism of food culture from the dimension of authenticity.

\section{Methodology}

Guangzhou food culture has a unique position in China. Since the reform and opening up, immigrants from the northeastern region have become an important component of Guangzhou immigrants, which is followed by the emergence of a large number of northeastern cuisine restaurants. There are apparent differences between northeastern food culture and Guangzhou food culture. The former has rough shape, deep color and heavy flavor, reflecting the roughness and boldness of northeastern culture; the latter excels in the variety of dishes and emphasizes nutrition. Besides, the differences of climate, region and culture between the Northeast and Guangzhou also have a significant impact. Northeastern food culture in Guangzhou is bound to create huge cultural conflicts, so it can be used as a typical case to do some research on translocal production of food culture. This study is based on "authenticity". When selecting cases, this paper focuses on two companies which have two extreme evaluations (high and low) on the degree of "authenticity" by consumers, and both are in good operating condition. Using "gourmet", "Northeast Cuisine", "no less than 40 yuan per capita consumption" as search keywords, the comprehensive evaluation of Dongbeiren Flavor Dumpling Restaurant (Garden Building Shop) (hereinafter called "Dongbeiren") ranked first on dianping.com, and field observation and interviews also showed that consumers generally recognized the authenticity of its products; while the authenticity evaluation of Northeast Dumpling Restaurant (Wanyihuaxuan Shop) (herein after called "Daozanjia") ranked at the bottom of the list, and interviews showed that both had good business performance.

More and more researchers from different fields use a variety of methods to study food culture [70,71]. This paper adopts a case study approach. Methods of data collection include: obtaining used texts from online media materials (customer reviews, site description, etc.); obtaining first-hand information through participant observation, in-depth interviews, photographs, etc. First, the researchers implemented 
pre-research to ensure the accessibility of research and determined the interview outline; Second, in the formal investigation stage, we went deep into the two restaurants, and got a comprehensive understanding of their development through interviews, observations and taking photos, in order to check out how they conduct food culture production, and how to combine culture authenticity and innovation. At the same time, this research discussed the interactive process of different participants by interviewing and observing consumers.

Text analysis of cultural products is a convenient way to conduct culture studies [7,29]. This research identified the process and mechanism of translocal production of food culture through in-depth analysis of a variety of qualitative text data, in order to determine which type of cultural production northeastern cuisine in Guangzhou belongs to. Throughout the research process, the triangulation method [72,73], namely studying the same object by differentiated data, investigators, research methods and theories, and a variety of ways to obtain various data sources (interviews, network evaluation, photographs, etc.), was used to complete the research.

Interviewees include: restaurant managers, chefs, waiters, and typical customer groups. Interview contents include the understanding of the production process of food culture (interviews with business-related personnel): first, whether cultural authenticity exists, and how to produce it; second, how to maintain authenticity, whether it has been consulted or negotiated, namely "negotiated authenticity" called by Cohen [50]. The mechanisms and processes of translocal production of food culture are analyzed, summarized, and concluded from the interviews. Because the research would judge the authenticity of enterprises from the perspective of the consumers' perception, the consumers are interviewed to see if their perception of northeastern cuisine is consistent with the enterprises, and the reasonableness of such a mechanism would be verified in the context of cultural commodification. There are 34 interviewees, including 15 consumers, 1 chef, and 1 representative waiter from "Dongbeiren" and "Daozanjia". The average length of interview is half an hour. Consumers cover three categories: consumers who come from the Northeast, have been to Northeast, and have not been to the Northeast. Consumers who come from the Northeast not only can remember the perceptions of local northeastern cuisine, but can judge out whether northeastern cuisine in Guangzhou has changed, and what the changes are; consumers who have been to the Northeast can also compare northeastern cuisine in two places, but unlike the former, they don't have home attachments to the Northeast; those who haven't been to the Northeast, but eat northeastern cuisine in Guangzhou, and we try to understand their experiences and perceptions.

\section{Results}

\subsection{Dongbeiren Flavor Dumpling Restaurant}

Based on the idea of building a hometown restaurant of black earth, Dongbeiren Flavor Dumpling Restaurant was founded on 1 January 1993 in Hainan. Until May 2013, the number of "Dongbeiren" restaurants has been more than 20. They are located in Beijing, Shanghai, Guangzhou, Shenzhen, Zhuhai, Hainan, Macao and other places. The corporate vision is to inherit, explore, develop and create the unique special food culture with black earth style in China, and to create a national food culture card with local characteristics. Using “original, authentic, green, healthy" as the fundamental concepts, "Dongbeiren" blends the traditional dishes with modern fad diets and pursues excellence. At the same 
time, it uses "natural and kind, festive and warm, unique style and moving" as fundamental concepts of service to make the "Dongbeiren" brand into people's heart. It has whole grains, vegetables, dumplings, and stews, almost covering all the northeast typical food, and its layout design and staff dress are full of Guangdong character and style. The Dongbeiren Flavor Dumpling Restaurant (Garden Building Shop), built in 1998, is located at 1-3/F, Garden Building, No.36, Road 2 of South Tianhe, Tianhe District, Guangzhou, China. In terms of decoration style and interior layout, in order to fully display the northeastern traditional culture, "Dongbeiren" uses a bright red color as mass-tone supplemented by the color of black earth, and its internal and external decor are in great harmony. Some of its raw materials are transported by air from the Northeast, such as wild herbs, northeastern rice, mutton, etc.

Waiters with a northeastern accent, agricultural implements, garlic, grains, handkerchiefs essential to northeastern Errenzhuan, fans, red paper-cuts, and a collection of northeast dialect, all highlight the design style of "Dongbeiren". Details such as paper towels, packaging of wet wipes, and menus design are consistent with the overall style. Compartments are named with northeastern features, such as "Beidahuang" "Gemen hall", "Zanjia" and so on. All the chefs are northeasterners with clear division of labor. The management personnel, from supervisor to executives, are also northeasterners. To maintain the consistency of service quality, the waiters have received systematic training: the dress with black and red is a symbol of the color of black earth and the enthusiasm of northeast; their language is specifically designed, for example, customers are called "brother, sister, little brother, little sister", and they are greeted loudly and enthusiastically with "welcome to our family" "come back home often", etc.

The names of dishes have a few characteristics: First, those traditional northeastern dishes, which are well-known and very popular can be found on the menu, such as Marinated Spare Ribs, Stewed Chick with Mushroom, Stewed Pork with Vermicelli, Fried Pork in Scoop, Candied Sweet Potato, Northeastern Dumplings, Straw Hat Pie, etc. Consumers said that "it is very joyful to see such a menu in Guangzhou". Second, the name design of dishes highlights characteristics of food. For example, it includes cooking techniques, such as meat braised in soy sauce, stewed, marinated or fried. In addition, in terms of visual perception, almost every dish is matched with pictures. Third, some names are combined with specific places, such as Zanjia Goubangzi roast chicken, Elunchun mutton string, or combined with the northeast natural wild raw materials, such as Brand Integrated Wild Mushroom Soup, Second Daughter-in-Law Fried Cabbage with Wild Mushroom, etc. At the same time, the names of dishes are also effected by the film and television play or sketch figures, calling in reality, and northeast dialect, such as Grandpa BiHearth Fish with Paste Cakes, Erzhuzi Wonderful Marinated Leg of Lamb, which make full use of various elements in northeastern culture. Some menu items even introduce the origin of the food, such as Demoli Stewed Live Fish.

The dishes display the bold and generous characteristics of northeasterners. The dishes are much more delicate with northeastern flavor. Northeasterners feel that the amount of dishes is relatively small compared with those in the Northeast, while other consumers depending on world of mouth or perception, especially after comparing with other cuisines, believe that its amount is enough. The lofty sentiments of large pieces of meat still exist, for example, Stewed Meat and Marinated Spare Ribs are large. A large bowl of wine is difficult to maintain, because Guangzhou customers drink white wine with a small wine cup, but the wine on shelves is still in large jars. Dishes from the material selection, design, to taste, appearance, etc., are trying to show the authentic face of northeastern cuisine, which the consumers are fully aware of, and they would make subtle adjustments according to consumers' demand to meet the 
needs of market. In addition, some performances are also designed. Take "Sun Island Zeibangzeibang dragon fish" for example. It could spurt fire in the first two minutes after taken to the table, which depends on spirit to sustain combustion state, and its visual effect is enjoyable. At the same time, the waiter is singing a short song about dragon fish and the consumers think it is quite unique. In general, the waiters would gather near specialties, and one leads them to say some blessings loudly so that everyone there will hear the words.

Although as a whole, consumers have perceived its authenticity through displays of strong local cultural features, there are some people who can not understand and accept some special designs. One consumer interviewed said that he couldn't accept it when the waiters called him elder brother, "I am not that old."

Consumers in Dongbeiren are varied, and they have different perceptions and feelings on northeastern food culture, so their demands for authenticity are also different. Consumers from the Northeast can be divided into two categories: ones that have their own independent judgments on whether the taste and forms of the dishes are in line with the requirements of authentic northeastern cuisine, such as, "the dishes are full of the taste of hometown, but are not as delicious as those at home", "can not be compared with mother's cooking, but the food is basically good enough". At the same time, they come to feel the atmosphere of "home": They feel kind due to the waiter's care and chat in Dongbei dialect, and when they see northeastern heated adobe bed and handkerchief for Errenzhuan, they feel taken back to the northeast and find the feeling of home. Another kind of consumer from the Northeast who do not quite understand about diet culture may be able to judge the quality of dishes and feel happy due to talk with Northeast people, but they won't be moved by adornment atmosphere of the restaurant. Customers who visited the Northeast pay more attention to whether the food itself is authentic or not. Some of the customers who have not been to the Northeast would like to know more about the restaurant and northeastern food culture, so they also have their own judgment standard. Most of them believe "Dongbeiren" is authentic and they come to experience the authentic northeastern food culture. Others who did not visit the Northeast tend to perceive little about culture. What they only care about is whether the dishes conform to their own taste or whether it is delicious. Sometimes they don't even judge. Their feelings depend on a friend's assessment. Thus, it is concluded that consumers having deep feelings for the Northeast will try to seek "feelings of home" or a "familiar atmosphere"; consumers familiar with northeastern culture will judge whether it is authentic according to the entire contents of the restaurant, but some cultural elements can't be recognized; consumers not familiar with the food culture of the Northeast will only evaluate the restaurant in terms of whether it is delicious or not, and will just be impacted by exaggerated colors. The latter two types of consumers are more inclined to experience the food culture of Northeast.

At the beginning of the establishment of "Dongbeiren", the dishes tasted a little salty, according to the original diet habits of Northeast, to attract northeasterners in consumer groups. With the increase of local consumers, and Guangdong food culture's impact on the Northeast consumers, "Dongbeiren" gradually adjusts its taste, until now it has been basically consistent with the level of consumers' demands. 


\subsection{Daozanjia Northeast Dumpling Restaurant}

The full name of Daozanjia Northeast Dumpling Restaurant is "Gospel to our Home" Northeast Dumpling Restaurant and it has been open for more than four years. The business owner is a Christian, hence the name is "Gospel to our Home". At present, it has seven restaurants, which are managed by the owner himself and his relatives. They do not focus on northeastern cuisine, but also run some pickled fish and hotpot restaurants. In this case study, the research location is at 2/F, Wanyihua Xuan, No. 10, Jinju Road, Haizhu District, Guangzhou, China. Its decorative design does not use northeastern culture elements. Except for the waiters' warm greetings, there is no difference in desktop decoration compared with any other restaurant and other decorations are not special. There is only one piece of calligraphy and painting hanged on each side of the wall, whose contents derive from the bible. Consumers are not very concerned about those things. When they were asked whether waiters are northeasterners, their answer was "should be". We cannot see that the consumers could feel its authenticity. They gave a poor evaluation on the environmental and health situation of the restaurant. The owner is a northeasterner, while almost none of the waiters and only some of the chefs are northeasterners, and there is no division of labor. Waiters are wearing red coats, but there are no obvious northeast culture characteristics. Without a unified design language, their service attitude is also serious and enthusiastic.

The restaurant provides typical northeast stewed dishes, such as the Northeast Farmers' Stewed Pork with Vegetables, Stewed Pork with Vermicelli, Stewed Chick with Mushroom and vermicelli, Northeast Dumplings, and so on. Consumers have different views on whether the taste is authentic. Some people believe that it is very authentic: "Both the name and the taste of the dishes are quite authentic" "Northeast Dumplings are really delicious" "Stewed Chick with Mushroom, dumplings, and Straw Hat Pie are really authentic". There is also much negative feedback, "I don't feel any outstanding taste here. Just so so. Maybe I don't like to eat northeastern cuisine", "The taste is very weak, not sweet". One cook said, "The restaurants in Guangzhou are different from those in the Northeast, and because the materials for many dishes cannot be compared to the local northeast, a gap exists in the taste of dishes." However, the characteristics of large amount and preferential price of northeastern cuisine is fully reflected here.

There are also many obvious non-northeast dishes, for example, Stir Fried Chicken, and Pickled Fish are popular Sichuan dishes, and griddle cooked dishes, such as Griddle Cooked Frog and Griddle Hand-Shredded Chicken, belong to Hunan Cuisine. In addition, there are some changes in the material selection and cooking techniques, for example, authentic northeastern cuisine generally cooks candied sweet potato, but "Daozanjia" has "candied fruit" on the menu. Consumers are clear about that and one consumer said, "I think there are a lot of Sichuan dishes which don't belong to northeastern cuisine. In addition, I am not sure whether some dishes are northeastern dishes or not." Instead of merely northeastern cuisine, the design of dishes is the combination of varied popular dishes from Sichuan Cuisine, Hunan Cuisine and other cuisines. In terms of northeastern dishes, producers try to cook authentic food, but it is not fully perceived by consumers. What they recognize is a large quantity of food, preferential price, and good taste.

Most consumers at "Daozanjia" live or work nearby. The number of northeastern consumers is much lower than "Dongbeiren". Consumers (who are from the Northeast and or have been to) who well understand and care about northeastern food culture would judge the authenticity of dishes deliberately, and it is easy to find a lot of non-northeastern dishes. Some people want to experience the feelings of 
their home region, but some dishes could not meet their expectations. However, it doesn't matter to those consumers (mainly who have not been to the Northeast) who don't understand or pay attention to northeastern cuisine. However, no matter what kind of consumer people are, the design of dishes here will create misleading information that consumers may mistake non-Northeast dishes as authentic Northeast food.

\subsection{The Comparison between Two Kinds of Food Culture Production}

Both the names of two restaurants show typical characteristics of Northeast culture, but there are differences in decoration style and environmental layout (Table 1). "Dongbeiren" pursues to display the traditional northeastern culture with red color as mass-tone supplemented by the color of black earth; "Daozanjia" has few northeastern culture elements. To dishes, the menu of "Dongbeiren" are full of authentic northeastern dishes with additional decorative services; "Daozanjia" has mixed authentic northeastern dishes with various other cuisines; consumers from two restaurants basically think both tastes are good, but "Dongbeiren" is more authentic. The chefs and managers "Dongbeiren" all come from Northeast and the waiters partly come from there; the owner of "Daozanjia" is Northeasterner, a few of the chefs are Northeasterners, and almost all the waiters are non-Northeasterners.

Both the consumer groups of "Dongbeiren" and "Daozanjia" include consumers who are from the Northeast, have been to the Northeast, and have not been to the Northeast (Table 1). For "Dongbeiren", there are a lot of consumers from the Northeast, but its proportion is dropping. For "Daozanjia", it mainly attracts consumers around, and the proportion of Northeast consumers is very low. Consumers choose "Daozanjia" mainly because of its low price and good taste instead of authentic Northeast dishes. Even some people come here for various kinds of cuisines. Consumers who well understand and care about the Northeast food culture would judge the authenticity of dishes deliberately; some people want to experience the feelings of hometown, but some dishes could not meet the expectation; authenticity are not important to those who don't understand or pay attention to northeastern cuisine.

Table 1. Two Kinds of Food Culture Production: Dongbeiren Flavor Dumpling Restaurant and Daozanjia Northeast Dumpling Restaurant.

\begin{tabular}{lll}
\hline Type & Authentic Food Culture Production & Differentiated Food Culture Production \\
\hline restaurant & Dongbeiren & Daozanjia \\
\hline location & $\begin{array}{l}\text { 300 m away from Shipaiqiao station of subway line 3; } \\
\text { relatively convenient, but the location is not very obvious }\end{array}$ & $\begin{array}{l}\text { Not close to the subway station, } \\
\text { but only 100 m away from Dajiangyuan } \\
\text { bus station, and its location is obvious. }\end{array}$ \\
\hline \multirow{2}{*}{ decoration } & $\begin{array}{l}\text { Rich in northeastern culture(color collocation of } \\
\text { black earth and bright red and green, full use of the } \\
\text { Northeast culture elements) }\end{array}$ & Almost no use of northeastern culture \\
\hline \multirow{2}{*}{ dishes } & $\begin{array}{l}\text { Authentic northeastern dishes, names with } \\
\text { geographical features. }\end{array}$ & $\begin{array}{l}\text { Part authentic northeastern dishes; } \\
\text { the names are simple; mixed with dishes } \\
\text { belonging to other cuisines. }\end{array}$ \\
\hline \multirow{2}{*}{ staff } & $\begin{array}{l}\text { The dress is consistent with the overall style, language are } \\
\text { standardized, all the Chefs, and managers, part of the } \\
\text { waiters are Northeasterners }\end{array}$ & $\begin{array}{l}\text { The dress is uniform, but has no special } \\
\text { meaning. The owner, part of chefs and } \\
\text { none of the waiters are northeasterners }\end{array}$ \\
\hline \multirow{2}{*}{ consumer } & $\begin{array}{l}\text { From everywhere, experience the culture, looking for the } \\
\text { feeling of "home", to experience "characteristic culture". }\end{array}$ & $\begin{array}{l}\text { Residents around and employees are main } \\
\text { consumers most for dining together }\end{array}$ \\
\hline
\end{tabular}




\subsection{The Translocal Production Mechanism of Food Culture}

The cases above show that there are at least two kinds of food culture production: "authentic food culture production" and "differentiated food culture production". The former can maintain a high degree of authenticity. The enterprise's name, decoration style, environmental layout, material procurement, design of dishes, waiters and so on, all keep to the original cultural tradition. For such kind of enterprises: if consumers have emotional appeals to the local culture, they would try to seek "the memory of home"; consumers who seek cultural experience of different places also tend to choose it. According to consumers' demand, the producers make some adjustments which do not touch the culture's essence, to display the intact food culture authentically. The latter has a low degree of authenticity. The restaurant chooses one kind of local cuisine as operational positioning, and has a distinctive name. However, it does not have local cultural characteristics in any respect and the design of dishes is the combination of varied popular dishes belonging to the local and others cuisines. Consumers of this kind of restaurant are not going to experience the culture, but choosing this restaurant for convenience and preferential price. Producers have given up the culture authenticity. Instead, they mix the features of food culture from different places to meet the demands of the mass market.

The producer-consumer system is a typical system in system engineering. Producers and consumers interact through the design of the restaurant environment and dishes, and the waiters' service: producers display the food culture to customers through the above aspects according to production intentions, and deliver an authentic or unauthentic food culture, while consumers will make reaction on perceived authenticity. If both aspects reach an agreement, it would reach a state of equilibrium. Otherwise, producers will make adjustments until consumers can accept it.

When consumers purchase food products, production and consumption almost happen at the same time. The production speed, service attitude, types of consumer groups and their own preferences and moods directly affect consumers' perceived quality of cultural products. Consumers can advise immediately, point out problems, and even ask for reproduction. At this moment, the modified products will vary from person to person, and tend to meet individual needs or to make unified adjustment according to the common requirements of most people, which are helpful to arrive at an instant balance because of reaching consumers' preferences. Authentic food culture production (Dongbeiren) will stick to authentic culture, and it will only make adjustments to accommodate local habitants' eating habits without changing the nature of its culture. This process shows a certain degree of fusion of at least two cultures. While differentiated food culture production (Daozanjia) continuously modifies the dishes according to consumers' degree of preference to a variety of popular cuisines, and basically gives up the culture authenticity.

\section{Conclusions}

In the translocal production process of food culture, authenticity is a necessary and changing concept in mobility context. Should translocal food culture transplant the authenticity from its original place? Most studies suggest that the authenticity of food culture is the determinant of successful operation for translocal food production. Translocal food needs to get its identification by maintaining authenticity [74], and would then outperform those competitors, which use similar services as ordinary goods for sale [6,11], like 
"Dongbeiren" and "Daozanjia". However, local knowledge could not keep the integrity of original cultural manifolds in the process of expansion, because it is also changed by the local knowledge and culture. Through constant collision and fusion, the final result is that the modified variant survives and occupies a strong position. In the process of locality transplantation, the core of authenticity does not change, but needs to adjust according to consumers' demand. A translocal themed restaurant will give up certain original truths to meet the demand of local customers [75]. For example, at Dongbeiren, the original dishes taste salty, but after some adjustments, the dishes become lighter, and their big wine bowl has been replaced by a small cup.

What translocal enterprises produce is not provided with objective authenticity, but constructive authenticity, even existential authenticity. Although "Dongbeiren" try to offer products of objectivism authenticity under the background of translocality, with northeastern characteristics displayed in as many aspects as possible, such as raw materials, the chefs, waiters, decoration, service and so on, it is impossible that all the raw materials are shipped from the Northeast and all the kitchen staff and waiters are northeasterners, so objective authenticity cannot be realized. That restaurants are in Guangzhou decides their unauthentic environment. Enterprises can only construct the Northeast food culture in Guangzhou through exaggerated colors, interesting names and elaborate design. At the same time, in order to meet the needs of the local market, enterprises have to make adjustments according to consumers' eating habits. These adjustments surely don't touch the nature of culture. If customers do not care about whether the red bricks on the wall and the farm implements are false or not, whether the bridal sedan-chair could be used or not, the theme, decoration style and specific decorations of the whole restaurant will make you feel like you are in the Northeast. Indeed, consumers will not consider whether this is objective reality. They believe it is northeastern food culture and full of northeastern characteristics, just because many things are performed as though they are real, such as the small table on the adobe bed, sweet corn, bright red and green colors, a strong northeastern accent, and so on. All these show constructivism authenticity [58]. Constructivist authenticity is still based on the prototypes of real experiences, while some forms of design have been considered to be separated from reality, and come out to be a postmodernist, and even existentialist authenticity of food culture. Postmodernist authenticity does not care about "real" or "not real", as long as there is enough experience, authenticity even can be created out of nothing $[41,58]$. Existentialist authenticity has been transferred from subject-concerned authenticity to object-perceived self-authenticity $[41,58,76]$. The performances in "Dongbeiren", such as singing a birthday song, creating a state of spurting fire and singing a short song about dragon fish by the waiter on the "Sun Island Zeibangzeibang dragon fish", are designed to provide the consumers with enough experiences. Consumers do not care about the authenticity, not even performed truth, and what they only pay attention to is whether the event really brings them unique experiences.

Authentic food culture production highlights the locality, and makes the locality have a symbolic meaning. To spread northeastern food culture, those production enterprises recognized by consumers to be fully authentic, pay great attention to the design of restaurant's culture, style and decoration, and have local features recognized by public through the commercialization of the local food culture, which play an important role in understanding and highlighting northeastern food culture [62]. The application of various forms of authentic culture, especially the use of exaggerated color and symbolic culture elements, allows consumers to have a deeper understanding of this type of cuisine, and some dishes, color and language 
have represented the Northeast food culture, and even the Kanto culture. For example, Marinated Spare Ribs, Fried Pork in Scoop, Stewed Pork with Vermicelli, Candied Sweet Potato and other dishes have been considered to be representatives of northeastern cuisine. Decorations, such as the northeastern heated adobe bed and bright red and green color also represent the Kanto culture. Therefore, the process of authentic food culture production is highlighting the Northeast locality, and dishes and culture with Northeast characteristics have become the symbol of Northeast.

Differentiated food culture production reshapes the locality and makes the local cultural boundaries become blurred. Although the positioning of the differentiated food culture production enterprise is one of regional cuisines with distinctive name, its dishes design, decoration style, service features and so on, are not for the purpose of the pursuit of authenticity. To meet the demand of the mass market, the restaurant continuously modifies the types of dishes according to the degree of consumers' preference to a variety of popular cuisines. Finally, the production mechanism would be formed with a fusion of the characteristics of food culture from different places and the culture authenticity are basically given up. At "Daozanjia", except for some typical local dishes, many other ones are difficult to determine what kind of cuisine they belong to. For example corn soup exists both in Hunan cuisine and northeastern cuisine, but as it appears in a northeastern cuisine restaurant, the consumers would naturally classify it as Northeast cuisine. That is to say, the positioning of the restaurant is the key. Whichever cuisine has more initiative, could expand its food culture border and reshape the locality. However, the expansion of food culture border and the reshaping of locality should not depend on "plunder" as a tool, because it blurs local cultural boundaries.

Compared with differentiated food culture production, authentic food culture production is helpful to the sustainable development of local food culture production. It protects the locality and at the same time transmits and develops the local culture. Culture production should not only be geared to local residents, but also to the public, even to the translocal production. As the urbanization process speeds up, and the economy develops rapidly, the new generation of northeasterners leave their native place, many original architectures, customs, and cultures in the northeastern countryside are replaced by the advanced technology and methods. Modern products are being copied constantly. As a result, it becomes more and more difficult to see the original Kanto culture. During the process of commercialization of culture, producers put innovative and authentic elements into products and bring new connotation to the products, which may become a sign or symbol of local culture [50]. This process is a kind of protection and inheritance of locality, and brings the Northeast food culture to consumers. No matter whether consumers are northeasterners or not, those who do not understand the culture can learn from it. From the changes of customers of "Dongbeiren", more and more non-northeastern people have recognized and accepted the northeastern food culture, which realizes the sustainable development mechanism of food culture's translocal production. While for the differentiated food culture production, due to the lack of authenticity, consumers' attention towards the authenticity of this kind of culture production was reduced. At this time, the restaurant's operational positioning will expand the boundary of food culture it represents, which is not conducive to the protection and development of specific food culture.

Translocal food culture production is a process, in which the producers and consumers continue to interact to maintain a state of equilibrium, which forms the sustainable development mechanism under the condition of a high degree of authenticity. From the view of enterprises' survival and development, and cultural preservation and heritage, to the authentic food culture production, the interaction range 
between producers and consumers is relatively small. Because its customers are various, from an extensive area and with different demands, it is necessary to keep its authentic image and word of mouth. While enterprises of the differentiated food culture production survive to profit because of single consumers group and geographical advantages. They don't focus on one specific food culture production and have no responsibility to protect the culture, so the interaction between producers and consumers is not strained. Therefore, authentic food culture production is more helpful to realize the sustainable development of food culture production.

Food culture production enterprises provide specific products based on the types of its customers, while consumers' perception of local food culture and their need for authenticity are different. Besides, to be authentic in the taste of the dishes, the authentic food culture production enterprise also uses atmosphere and decoration design to build distinctive characteristics of northeastern culture, which is very attractive to those who want to look for experiences of "the feelings of home" "the memory of home" and a "familiar atmosphere". Therefore, these people occupy a large proportion in all consumers. They tend to judge the authenticity of food according to their own experiences of perception. Those consumers who seek cultural experience of other places also tend to select this kind of restaurant, and the matching of restaurant atmosphere and environment with the food culture would increase their satisfaction. In the differentiated food culture production enterprises, consumers who have the need of those two cultural experiences are very few. Consumers there are present more for convenience and affordable dishes. Because they are unfamiliar with northeastern food culture, the dish design here would mislead them to take dishes that belong to other cuisines, rather than the northeastern cuisine, just because they are being served in a northeastern restaurant.

This study, from the perspectives of the cultural production and customer perception, compares the development mechanism of two production types, and analyzes the interaction between producers and consumers, which is a complement to the existing researches [7,20], especially a supplement and development for authenticity and sustainable development theory $[41,43,45,47,49,50,68,69]$. Through study on specific cases, it makes important theoretical contributions to exploring the sustainable development mechanism of local cultural production in the area of food culture. It is also a supplement and development of the theoretical system of translocal culture production to combine the enterprise development with the locality of food culture and combine the translocality with food production and sustainable development with the aid of multi-disciplinary theory and practical experience. This study would also provide a theoretical basis for the translocal spread of food enterprises. From the perspective of cultural fusion, constructive authenticity can be used as a characteristic of cultural fusion, while cultural fusion is one of the important reasons for the generation of constructive authenticity. The generation process of constructive authenticity is the process of cultural fusion.

With regard to the deficiencies, this paper only chose the production of northeastern cuisine in Guangzhou as a study case, while quantitative research has not been conducted. The study of interaction between producers and consumers is a long-term process. During the period of investigation, we got information about the situation only by the interview and short-term observation. If long-term tracking were used, research data would have been more accurate. Future research can study the spatial distribution of northeastern cuisine, and the relationship between such distribution and migration or cultural consumption from a more macro perspective. In addition, the paper focused only on one dimension - authenticity, while other dimensions can also be considered. 


\section{Acknowledgments}

This work was supported jointly by the National Natural Science Foundation of China (Grant No. 41201140, 41201137 and 41301140). The authors would like to thank the supports of two restaurants and all interviewees who took part in this study.

\section{Author Contributions}

Guojun Zeng contributed to the development of the conceptual framework and research design. Yongqiu Zhao contributed to the case development, data analysis and writing of the article. Shuzhi Sun contributed to data collection and writing parts of the article. All authors read and approved the final manuscript.

\section{Conflicts of Interest}

The authors declare no conflict of interest.

\section{References}

1. Liu, H.; Lin, L. Food, culinary identity and transnational culture: Chinese restaurant business in Southern California. J. Asian Am. Stud. 2009, 6, 135-162.

2. Chen, C.K. The culture of Chinese diet regional differentiation and developing trends. Acta Geogr. Sin. 1994, 49, 226-235.

3. Amy, B.; Trubek, X. The Taste of Place: A Cultural Journey into Terroir; University of California Press: Berkeley, CA, USA, 2008.

4. Harvey, D. The Condition of Postmodernity; Brasil Blackwell: Oxford, UK, 1989; pp. 260-283.

5. Pietrykowski, B. You are what you eat: The social economy of the slow food movement. Rev. Soc. Econ. 2004, 62, 307-321.

6. Sims, R. Food, place and authenticity: Local food and the sustainable tourism experience. J. Sustain. Tour. 2009, 17, 321-336.

7. Zeng, G.J.; Sun, S.Z.; Zhu, H. Translocal restaurants' cultural production under the paradox of globalization and locality: Case studies from Guangzhou. Sci. Geogr. Sin. 2013, 33, 291-298.

8. Zhu, H.; Qian, J.X.; Chen, X.L. Place and identity: The rethink of place of European-American Human Geography. Hum. Geogr. 2010, 25, 1-6.

9. Massey, D. For Space; Sage Publications Inc.: London, UK, 2005.

10. Xue, X.M.; Ye, W. The study on the mechanism of change of traditional eco-culture under the impact of tourism in ethnic communities, Northwest Yunnan. Guizhou Eth. Stud. 2011, 32, $108-114$.

11. Zeng, G.J.; Go, F.; de Vries, H. Paradox of authenticity vs. standardization: Expansion strategies of restaurant groups in china. Int. J. Hosp. Manag. 2012, 31, 1090-1100.

12. Butler, J. Contingent foundations: Feminism and the question of "postmodernism". In Feminists Theorize the Political; Butler, J., Scott, J., Eds.; Routledge: London, UK, 1992; pp. 3-21.

13. Shi, H.M. Our Country's Different Geographical Food Culture Research in Geography Teaching. Master's Thesis, Hebei Normal University, Hebei, China, 27 May 2010. 
14. Cai, X.M.; Zhu, H.; SiTu, S.J. Guangdong cooking culture landscapes and their regional differences. Trop. Geogr. 2011, 31, 321-327.

15. Zhao, R.G.; Xie, D.Y. An Introduction to Dietary Culture; China Light Industry Press: Beijing, China, 2000.

16. Hegarty, J.A.; O’Mahony, G.B. Gastronomy: A phenomenon of cultural expressionism and an aesthetic for living. Int. J. Hosp. Manag. 2001, 20, 3-13.

17. Lan, Y. The reasons and distribution of pungent flavor districts in China's dietetics. Geogr. Res. 2001, 20, 229-236.

18. Cai, X.M.; SiTu, S.J. A review on the studies of food culture from geographical perspective. Yunnan Geogr. Environ. Res. 2006, 18, 83-88.

19. Hammer, R.B. Recreation and rural development in Norway: Nature vs. culture. Scand. J. Hosp. Tour. 2008, 8, 176-186.

20. Zeng, G.J.; Liu, X.Y. Paradox of standardization and authenticity: Expansion modes of hotel groups. Tour. Trib. 2011, 26, 24-29.

21. Valli, C.; Traill, W.B. Culture and food: A model of yoghurt consumption in the EU. Food Qual. Pref. 2005, 16, 291-304.

22. Dube, L.; LeBel, J.L.; Lu, J. Affect asymmetry and comfort food consumption. Physiol. Behav. 2005, 86, 559-567.

23. Chrea, C.; Valentin, D.; Sulmont-Rosse, H.C. Culture and odor categorization agreement between cultures depends upon the odors. Food Qual. Pref. 2004, 15, 669-679.

24. Grigg, D. The nutritional transition in Western Europe. J. Hist. Geogr. 1995, 22, 247-261.

25. Freidberg, S. French beans for the masses: A modern historical geography of food in Burkina Faso. J. Hist. Geogr. 2003, 29, 445-463.

26. King, C.S.; Weber, J.A.; Herbert, L. The effect of meal situation, social interaction, physical environment and choice on food acceptability. Food Qual. Pref. 2004, 15, 645-653.

27. Ericksen, J.P. Change: Emerging challenges. Environ. Sci. Pol. 2009, 12, 373-377.

28. Christopher, A.; Taylor, C.A.; Kathryn, S. Impact of core and secondary foods on nutritional composition of diets in Native-American women. J. Am. Diet. Assoc. 2005, 105, 413-419.

29. Peterson, R. The production of culture: A prolegomenon. Am. Behav. Sci. 1976, 19, 669-684.

30. Peterson, R.; Anand, N. The production of culture perspective. Ann. Rev. Sociol. 2004, 30, 311-334.

31. Mitchell, D. Cultural Geography: A Critical Introduction; Blackwell Publisher: Oxford, UK, 2000.

32. Wu, H.Y. On the multi-regionality of Hong Kong literature. J. PKU (Phil. Soc. Sci.) 2007, 44, $50-57$.

33. Mee, W. A traffic in Songket: Translocal Malay identities in Sambas. J. Southeast Asian Stud. 2010, 41, 321-339.

34. Waterman, S. Place, culture and identity: Summer music in Upper Galilee. Trans. Inst. Br. Geogr. 1998, 23, 253-267.

35. Mitchell, D. There's No Such Thing as Culture: Towards a Reconceptualization of the Idea of Culture in Geography; Institute of British Geographers: London, UK, 1995.

36. Zhou, S.Y. Anglo-American cultural Studies and the New Cultural Geography. Acta Geogr. Sin. 2004, 59, 162-166. 
37. Nijman, J. Cultural globalization and the identity of place: The reconstruction of Amsterdam. Cult. Geogr. 1999, 6, 146-164.

38. Bhabha, K.H. The Location of Culture; Routledge Taylor \& Francis Group: New York, NY, USA, 1994.

39. Tang, X.F.; Zhou, S.Y.; Li, L.L. The concept of super-organism in the study of cultural geography. Geogr. Res. 2008, 27, 431-438.

40. MacCannell, D. Staged authenticity: Arrangements of social space in tourist settings. Am. J. Sociol. 1973, 79, 589-603.

41. Wang, N. Rethinking authenticity in tourism experience. Ann. Tour. Res. 1999, 26, 349-370.

42. Zeng, G.J.; Liu, M. Food geography and the translocal production of food culture. Tour. Trib. 2013, $3,9-11$.

43. Jamal, T.; Hill, S. Developing a framework for indicators of authenticity: The place and space of cultural and heritage tourism. Asia Pac. J. Tour. Res. 2004, 9, 353-371.

44. Boorstin, D.J. The Image: A Guide to Pseudo-Events in America; Atheneum: New York, NY, USA, 1964.

45. MacCannell, D. The Tourist: A New Theory of the Leisure Class; Schocken Books: New York, NY, USA, 1976.

46. MacCannell, D. The Tourist: A New Theory of the Leisure Class, 2nd ed.; Shocken Books: New York, NY, USA, 1989.

47. Wang, N. Interactive Authenticity in Tourism-A Case Study on Hospitality Tourism. J. Guangxi Univ. Nat. (Phil. Soc. Sci.) 2007, 6, 18-24.

48. Ma, L. On the application of the concept of authenticity in tourism research. Tour. Trib. 2007, 10, 76-81.

49. Sedmak, G.; Mihalic, T. Authenticity in mature seaside resorts. Ann. Tour. Res. 2008, 35, 1007-1031.

50. Cohen, E. Authenticity and commoditization in tourism. Ann. Tour. Res. 1988, 15, 371-386.

51. Cohen, E. Primitive and remote: Hill trekking in Thailand. Ann. Tour. Res. 1989, 16, 30-61.

52. Chang, R.C.Y.; Kivela, J.; Mak, A.H.N. Food preferences of Chinese tourists. Ann. Tour. Res. 2010, 37, 989-1011.

53. Mkono, M.A. Nethnographic examination of constructive authenticity in Victoria Falls tourist (restaurant) experiences. Int. J. Hosp. Manag. 2012, 31, 387-394.

54. Lau, R.W.K. Revisiting authenticity: A social realist approach. Ann. Tour. Res. 2010, 37, 478-498.

55. Wang, Y. Customized authenticity begins at home. Ann. Tour. Res. 2007, 34, 789-804.

56. Robinson, N.S.R.; Clifford, C. Authenticity and festival food service experiences. Ann. Tour. Res. 2012, 39, 571-600.

57. Prentice, R. Experiential cultural tourism: Museums \& the marketing of the new romanticism of evoked authenticity. Mus. Manag. Curator. 2001, 19, 5-26.

58. Guan, J.J. What is the authenticity of food culture heritage? In Keep the Memory of Ancestors' Table, Proceedings of the 2011 "Hangzhou" food study BBS on Asia, Hangzhou, China, 17-19 August 2011; pp. 812-819.

59. Grove, A.M. Authentic British food products: A review of consumer perceptions. Int. J. Consum. Stud. 2001, 25, 246-254. 
60. Wang, Y.L. Study on sustainable development of Qinhuai culinary culture. Jiangsu Condiment Subsid. Food 2013, 135, 42-44.

61. Liu, Y.Q. Research on the ethnic catering culture features and sustainable development in Western. J. Nanning Polytech. 2010, 1, 10-13.

62. Xu, Y.S.; Dong, S.D. An initial survey on sustainable development of culture. J. Harbin Univ. 2009, $9,5-8$.

63. Deng, D. Study on the sustainable development of the traditional food brand in Guangzhou. Southeast Commun. 2007, 10, 172-173.

64. Marsden, T.; Smith, E. Ecological entrepreneurship: Sustainable development in local communities through quality food production and local branding. Geoforum 2005, 36, 440-451.

65. Sundkvist, Å.; Milestad, R.; Jansson, A.M. On the importance of tightening feedback loops for sustainable development of food systems. Food Pol. 2005, 30, 224-239.

66. Zhu, Y.Q. Cultural ecology protection and sustainable cultural development: With reference to the protection of intangible cultural heritages in China. J. Shandong Univ. (Phil. Soc. Sci.) 2012, 2, $156-160$.

67. Zhang, W.; Fang, X.L.; Zhang, X.Y. A study on sustainable tourism attraction enhancement of Yinruins as World Cultural Heritage-On new perspective of tourism product authenticity development. J. Beijing Int. Stud. Univ. 2009, 5, 60-66.

68. Goodman, S.G.D. Shanxi as translocal imaginary: Reforming the local. In Translocal China Linkages, Identities, and the Reimagining of Space; Oakes, T., Schein, L., Eds.; Routledge: London, UK, 2006; pp. 56-73.

69. Oakes, T.; Schein, L. Translocal China Linkages, Identities, and the Reimagining of Space; Routledge: London, UK, 2006.

70. Belasco, J.; Scranton, P. Food Nations: Selling Taste in Consumer Societies; Routledge: New York, NY, USA, 2002.

71. Freedman, P. Food: The History of Taste; University of California Press: Berkeley, CA, USA, 2007.

72. Denzin, N.K. The Research Act: A Theoretical Introduction to Sociological Methods; Prentice-Hall: Englewood Cliffs, NJ, USA, 1989.

73. Li, Z.G.; Xue, D.S.; Du, F. The local response of transnational social space under globalization in urban China: A case study of African enclave in Guangzhou. Geogr. Res. 2009, 28, 920-932.

74. Hughes, G. Authenticity in tourism. Ann. Tour. Res. 1995, 22, 781-803.

75. Waitt, G. Consuming heritage: Perceived historical authenticity. Ann. Tour. Res. 2000, 27, $835-862$.

76. Grayson, K.; Martinec, R. Consumer perceptions of iconicity and indexicality and their influence on assessments of authentic market offerings. J. Consum. Res. 2004, 31, 296-312.

(C) 2014 by the authors; licensee MDPI, Basel, Switzerland. This article is an open access article distributed under the terms and conditions of the Creative Commons Attribution license (http://creativecommons.org/licenses/by/4.0/). 